\title{
The Role of the Article in the Semantic Interpretation of the Antecedent in Attributive Clauses
}

\author{
Nune Hayrapetyan \\ Yerevan State University
}

$\mathrm{T}$ he study of the article in English has a long tradition in various disciplines, including linguistics, philosophy, logics and psychology. It has been analyzed from a variety of distinct theoretical perspectives - logical semantics, functionalism, psycholinguistics, computational linguistics, to mention just a few. Nevertheless, previous analyses of the definite article the are remarkably similar in both the kinds of data they examine and the general theoretical questions they attempt to answer. More specifically, research has consistently focused on what we might call the "referential function" of the article, that is, the use of a noun phrase with the to pick out an individual, "to distinguish it from all other individuals in the universe of discourse" (Lyons 1977).

The article certainly plays a very important role in grammar. The paper focuses on the use of the article in restrictive and non-restrictive attributive clauses. Grosu \& Landman (1998) interpreted restrictive (defining) relatives as intersective modifiers of the nominal head which contribute to determining the restriction of the determiner, whereas nonrestrictive (appositive or non-defining) relatives modify the whole noun phrase head, rather than contributing to the restriction.

According to Huddleston (1971) relative clauses are characterized by the presence in their remote structure of an element that is co-referential with a preceding element, its antecedent. Normally the relativized element and its antecedent are NPs.

The modification of the antecedent by the relative clause can be restrictive and nonrestrictive. In restrictive relatives, the relativized NP and its antecedent are both dominated in the remote structure by a larger NP, which is the matrix NP.

In non-restrictive relatives the antecedent and the relative clause do not form a constituent in the remote structure:

a) The doctor, who was the family physician, saluted him, but he scarcely took any notice.

b) The doctor who was the family physician saluted him, but he scarcely took any notice.

In (a) the speaker assumes that the hearer is able to uniquely identify which doctor he is referring to. The hearer may make the identification on the basis of the preceding context or of his knowledge of the situation, whereas in (b) the hearer is assumed to be able to identify which doctor is being referred to. Thus, the doctor who was the family physician is a single constituent NP. The difference between these two types is that in restrictive relatives, the relativized NP and its antecedent are both dominated in the remote structure by a larger NP, which is the matrix NP, whereas in non-restrictive relatives the antecedent and the relative clause do not form a constituent in the remote structure.

The definite article expresses what is known, or what is not presented as new, and has 
the function of identification, while the indefinite article expresses what is new and has the function of relative generalization.

It is suggested that articles be represented in the deep structure as syntactic features on the head noun. There is no such category as article in the phrase structure.

Views on definiteness are widely divergent. Perlmutter (1970) has given the impression that the comes solely from lexical insertion. Robbins (1968) states that all instances of the arise transformationally. In considering the sources of definite articles, there are several distinct types of them to be considered:

1. anaphoric (within a sentence),

2. definite description with a relative clause,

3. non-linguistically anaphoric (contextual).

These 3 types of uses do not exhaust the significant classifications, the lines between them are easy to draw or to justify.

We consider that type 1 is simply a special case of type 3 , i.e. there is the same process of anaphora in both, and it is a relatively superficial matter whether the antecedent happens to be in the same sentence or not. One might claim that the use of the definite article depends on an implicit relative clause which ensures uniqueness and hence definiteness.

It is assumed (Baker 1989) that anaphora changes the kernel indefinites to derived definite and the is inserted transformationally when an underlying existential relative sentence is embedded with the determiner.

In the case of the anaphoric definite article, the NP is assumed to be coextensive with the previous NP which caused the definitization. When the definite article occurs with a relative clause, it (the clause) defines the set. The fact that some occurrences of the definite article are obligatory does not really provide justification for any of the above positions.

The definite article obligatorily accompanies superlatives, as well as other quantifiers such as same, only, next which require a certain noun, as in: the best way, the same day, etc. Articles operate identically with proper and countable common nouns except that the definite article is zero before singular proper nouns.

Chomsky (1965) adopted a formulation, on which the relative clause is generated as a complement to the determiner. The proposed selectional relation between the determiner and the relative clause can straightforwardly account for the following co-occurrence constraints:

a) the zero determiner introducing (unmodified) proper names allows only for nonrestrictive relatives and not for restrictives;

b) the definite and indefinite article allow for both non-restrictives and restrictives;

c) quantificational determiners allow only for restrictives, but not for non-restrictives.

It also accounts for the behaviour of certain abstract common nouns, like manner, way, time, place, which can only occur when modified by a relative clause or by some kind of demonstrative determiner.

Both men of childhood, of the elfin and adventurous time when tall weeds close over us like woods had simultaneously a reminiscence.

(Chesterton "The Innocence of Father Brown” p.172) 
As soon as I arrived I made an attempt to find my host but the two or three people of whom I asked his whereabouts stared at me in such an amazed way and denied so vehemently any knowledge of his movements that I slunk off in the direction of the cocktail table-the only place in the garden where a single man could linger without looking purposeless and alone.

(Fitzgerald "The Great Gatsby" p.57)

Similarly, it accounts for the observation that a proper name can be preceded by the definite article when it is modified by a restrictive relative clause: the Paris (that I love). $A$ refers to what is unidentified, whereas the refers to what is identified. There is, of course, no one-to-one correspondence between the use of the indefinite article and what is unidentified on the one hand, and the definite article and what is identified on the other. For example, with cataphoric determination, the definite article does not refer to an identified element. Generic utterances provide another exception, and soon. However, in this discussion,we propose to simplify and to state that:

the reference of an antecedent accompanied by the indefinite article is considered to be non-retrievable in context/situation;

the reference of an antecedent accompanied by the definite article is considered to be retrievable in context/situation.

Many if not most linguists and grammarians tend to use definite head examples when analysing the properties of the restrictive relative clause. This leads one to assume that no distinction needs to be made between restrictive clauses with definite heads and those with indefinite ones. One assumes that both play the same role but in fact this is not the case. The non-retrievable vs. retrievable parameter just mentioned has semantic and pragmatic implications which, in turn, trigger off not only semantic and pragmatic distinctions but also syntactic ones.

It is a well-known fact that in written English the comma ought to be used if the utterer wishes to indicate that the relative clause is a non-restrictive one; this necessity is, of course, explained by the fact that, with a definite head, there can be referential ambiguity if the comma is omitted:

The storm was particularly cruel to the Spanish ships which had taken the worst punishment in the battle. (Thomson "Sir Francis Drake" p.57)

According to whether the comma was omitted or not, the storm was particularly cruel to all the Spanish ships (non-restrictive); or else it was cruel only to those which had taken the worst punishment (restrictive).

However, for a non-generic reference, there can be no referential ambiguity when the comma is omitted if the head is indefinite. It is not possible for there to be any confusion of reference for an element presented for the first time. There seems to be only one exception to this - the case where the antecedent comprises more than one noun: 
These were, however, reassured by his confidential servant, Ivan, the old man with a scar, and a face almost as grey as his moustaches, who always sat at a table in the entrance hall - a hall hung with weapons.

(Chesterton "The Innocence of Father Brown" p.30)

Here, the comma indicates that the whole noun phrase is referred to; in other words, it is not the scar or the face that sat at a table but Ivan, the old man with a scar.

Since, for indefinite heads, the comma is normally not required to solve problems of referential ambiguity, this means that for the most part they (relatives with indefinite heads) have the syntactic and suprasegmental features of the attached relative clause. The example just mentioned, provides an exception. Another exception is the continuative relative clause:

And every time the matrons of Atlanta gathered together to gossip, his reputation grew worse, which only made him all the more glamorous to the young girls.

(Mitchell "Gone With the Wind" p.185)

Here, his being made more glamorous to the young girls cannot enter the description of its referent at the time of the event referred to in the matrix clause (the gatherings of the matrons of Atlanta); only on a subsequent occasion can it do so (his reputation grew worse among the matrons of Atlanta which made him more and more glamorous to the young girls).

This type of exception, where a comma indicates the non-restrictive status of the relative clause, helps one to understand why, for pragmatic reasons, it is necessary that there be two main types of relative clause: restrictive and non-restrictive. The opening of a new tone unit, marked by the comma and indicating the non-restrictive status of the clause serves as a warning to the addressee. This warning can be interpreted as follows: the information contained in the relative clause does not contribute towards the description of the antecedent for purposes of identification. Parallely,in the interpretation of the antecedent the role of the article is to be emphasized.

(1) The man, who has blue eyes, is very handsome.

(2) The man who has blue eyes is very handsome.

Sentence (1) assumes that we already know what man is being talked about-hence the definite article the. That he has blue eyes is just an additional piece of information, possibly relevant to the judgment that he is handsome. Sentence (2) assumes that we have been talking about more than one man and that we are singling out the one with blue eyes for a favorable comment.

We are dealing with the one man on earth, perhaps, who has taken no more than his due. (Chesterton"The Innocence of Father Brown" p.142)

Only Gatsby, the man who gives his name to this book, was exempt from my reaction-Gatsby who represented everything for which I have an unaffected scorn.

(Fitzgerald "The Great Gatsby" p.4)

I am a man who has ever since boyhood believed in Nature and in all 
natural functions and instincts, whether men called them moral or immoral. (Chesterton "The Innocence of Father Brown" p.167)

And I thank God that I see the criminal clearly now because he is a criminal who cannot be brought to the gallows.

(Chesterton "The Innocence of Father Brown" p.210)

The distinction between restrictive and non-restrictive applies to other forms of postmodifiers as well, particularly to noun phrases:

(1) My brother Bill laughed.

(2) My brother, Bill, laughed.

(3) My brother who is a doctor laughed.

(4) My brother, who is a doctor, laughed.

(5) Bill, who is a doctor, laughed.

You would always use sentence (1) above if you have more than one brother and want to specify which one. Sentence (2) implies that you have only one brother but want to remind the listener or reader what your brother's name is. Sentence (3) has a restrictive relative clause implying that you have more than one brother, with only one brother being a doctor. Sentence (4) implies either that you have only one brother or that your reader already knows which brother is being talked about. Unless there were, say, a whole room full of people named Bill, relative clauses modifying names, like (5) above, are always non-restrictive.

We can distinguish three functions of relative clauses:

a) identifying RCs enable reference identification

Which book did you buy? The book (that deals with syntax).

b) classifying RCs create new reference subclasses

What kind of book are you looking for? A book (that deals with syntax).

c) describing RCs provide additional information

What kind of book did you buy? A book (that deals with syntax).

Relative clauses that modify definite noun phrases can have a describing function in which case they are non-restrictive in form. RCs that modify indefinite noun phrases on the other hand, cannot have an identifying function. They can have a classifying function, in which case they are restrictive in form, or they can have a describing function, in which case they are non-restrictive in form. So articles should be represented in the deep structure as syntactic features on the head noun. It is suggested that "kernel" sentences have only indefinite articles and it is anaphora that changes the kernel indefinites to derived definites. Thus definitization ensures the conversion of constituent indefinite articles to definite status which embraces three types of definite articles: anaphoric (within a sentence), definite description with relative clause, and non-linguistically anaphoric (contextual).

\section{References:}

1. Baker, C. (1989) English Syntax. Cambridge: MIT Press.

2. Chomsky,N. (1965) Aspects of the Theory of Syntex. Cambridge. MA: MIT Press. 
3. Grosu, A. (2002) Strange Relatives at the Interface of Two Millenia. Tel Aviv: Tel Aviv University.

4. Huddleston, R. (1971) The Sentence in Written English. Cambridge: CUP.

5. Jacobs, R. (1995) English Syntax.A Grammar for English Language Professionals. Oxford: Oxford University Press.

6. Lyons, J. (1977) Semantics. Cambridge: CUP.

7. Perlmutter, D. (1970) On the Article in English. Cambridge: MIT Press.

8. Quirk, R.; Greenbaum, S.; Leech, G. and Svartvik, J. (1985) A Comprehensive Grammar of the English Language. London: Longman.

9. Robbins, B. (1968) The Definite Article in English Transformations. The Hague: Mouton.

\section{Sources of Data:}

1. Chesterton,G. (2001) The Innocence of Father Brown. London: Penguin Book Ltd.

2. Fitzgerald, S. (1991) The Great Gatsby. Cambridge:CUP.

3. Mitchell, M. (1936) Gone with the Wind.New York: MacMillan.

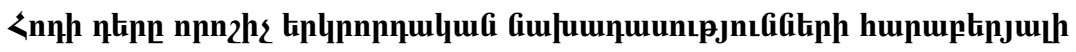

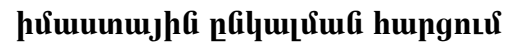

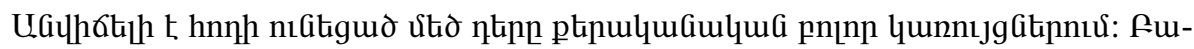

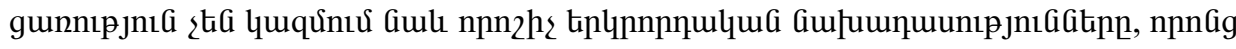
hupuptipjüh htin oqunuqnnò

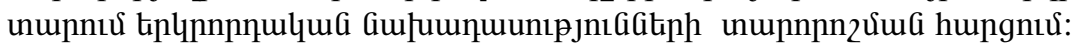

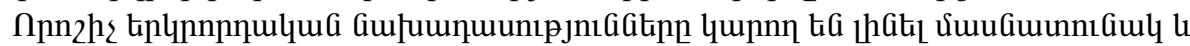

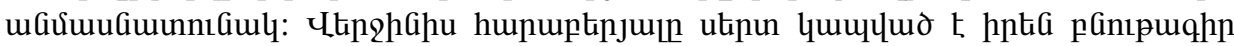

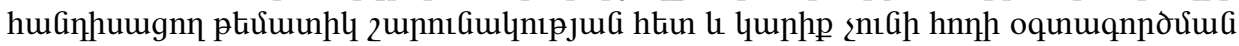

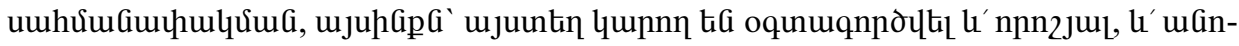

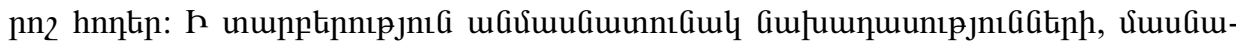

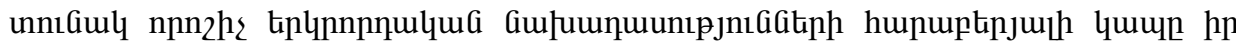

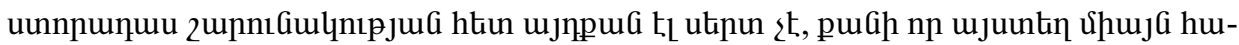

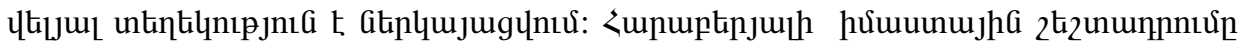

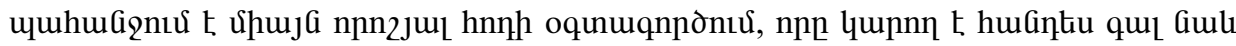

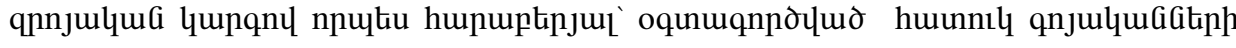

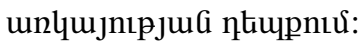

